\title{
Particle Board and Oriented Strand Board Prepared with Nanocellulose-Reinforced Adhesive
}

\author{
Stefan Veigel, ${ }^{1}$ Jörn Rathke, ${ }^{2}$ Martin Weigl, ${ }^{2}$ and Wolfgang Gindl-Altmutter ${ }^{1}$ \\ ${ }^{1}$ Department of Material Sciences and Process Engineering, Institute of Wood Science and Technology, \\ BOKU-University of Natural Resources and Life Sciences, University Research Center Tulln (UFT), Konrad Lorenz Straße 24, \\ 3430 Tulln, Austria \\ ${ }^{2}$ Wood K plus, Competence Center for Wood Composites and Wood Chemistry, Altenberger Straße 69, 4040 Linz, Austria
}

Correspondence should be addressed to Stefan Veigel, stefan.veigel@boku.ac.at

Received 16 January 2012; Accepted 9 April 2012

Academic Editor: Tong Lin

Copyright (c) 2012 Stefan Veigel et al. This is an open access article distributed under the Creative Commons Attribution License, which permits unrestricted use, distribution, and reproduction in any medium, provided the original work is properly cited.

\begin{abstract}
Adhesives on the basis of urea-formaldehyde (UF) and melamine-urea-formaldehyde (MUF) are extensively used in the production of wood-based panels. In the present study, the attempt was made to improve the mechanical board properties by reinforcing these adhesives with cellulose nanofibers (CNFs). The latter were produced from dissolving grade beech pulp by a mechanical homogenization process. Adhesive mixtures with a CNF content of 0,1 , and $3 \mathrm{wt} \%$ based on solid resin were prepared by mixing an aqueous CNF suspension with UF and MUF adhesives. Laboratory-scale particle boards and oriented strand boards (OSBs) were produced, and the mechanical and fracture mechanical properties were investigated. Particle boards prepared with UF containing $1 \mathrm{wt} \%$ CNF showed a reduced thickness swelling and better internal bond and bending strength than boards produced with pure UF. The reinforcing effect of CNF was even more obvious for OSB where a significant improvement of strength properties of $16 \%$ was found. For both, particle board and OSB, mode I fracture energy and fracture toughness were the parameters with the greatest improvement indicating that the adhesive bonds were markedly toughened by the CNF addition.
\end{abstract}

\section{Introduction}

Almost 80 years after its invention, particle board still represents the by far most important group of wood-based panels in Europe. In 2010, the share of particle board in the overall wood-based panel production was around 63\% [1]. Apart from particle board, oriented strand board (OSB) is becoming increasingly important in both decorative and structural applications. For use as a construction material, mechanical board properties are of vital importance. In this regard, the quality of connections between wood particles is a key factor, which in turn is determined by the amount and type of adhesive used. In wood-based panel production, aminoplastic adhesives on the basis of urea-formaldehyde (UF) and melamine-urea-formaldehyde (MUF) are prevalent. These adhesives offer a number of advantages for industrial application; however, the mechanical performance of UF and MUF wood adhesive bonds is limited. Since the elastic modulus of cured aminoplastic bond lines is high, the deformation of the adhesive layer under mechanical loading is usually small. As a result, stress concentrations along the bond line of a wood adhesive joint are generated [2-4] that reduce the overall strength of the joint.

In the past, various attempts have been made to reduce the brittleness of UF and thus enhance its strength properties. The approaches range from chemical modification of the UF polymer or blending with other polymers (e.g., [5-11]) to the reinforcement with different kinds of fibers. Since UF resins are known to have a strong adhesion to most cellulosecontaining materials, cellulose-based fibers seem well suited for reinforcing UF. This was confirmed experimentally by a number of studies (e.g., [12-17]). Since, in particle board production, the adhesive is atomized into fine droplets about $40-60 \mu \mathrm{m}$ in diameter prior to the binding of wood particles, reinforcing elements need to be micro- or nano sized [18]. Consequently, the application of cellulose nanofibers (CNFs) for adhesive reinforcement seems promising. 
TABLE 1: Composition and properties of adhesive mixtures.

\begin{tabular}{|c|c|c|c|c|c|c|c|c|}
\hline \multirow{2}{*}{ Adhesive mixture } & \multicolumn{3}{|c|}{ Quantity (g/100 g adhesive mixture) } & \multirow{2}{*}{$\begin{array}{l}\text { Hardener } \\
\text { (g solid) }\end{array}$} & \multirow{2}{*}{$\begin{array}{c}\text { Solid resin } \\
(\%)\end{array}$} & \multirow{2}{*}{$\begin{array}{c}\text { Cellulose } \\
\text { (\% of solid resin) }\end{array}$} & \multirow{2}{*}{$\begin{array}{l}\text { Gel time } \\
\text { (s) }\end{array}$} & \multirow{2}{*}{$\begin{array}{c}\text { Viscosity } \\
(\mathrm{Pa} \cdot \mathrm{s})\end{array}$} \\
\hline & Resin & Cellulose & Water & & & & & \\
\hline UF & 66.00 & - & 34.00 & 1.65 & 66.0 & - & 49 & 0.48 \\
\hline MUF & 45.00 & - & 55.00 & - & 45.0 & - & 75 & 1.62 \\
\hline UF-1\% CNF & 45.55 & 0.46 & 53.99 & 1.14 & 45.6 & 1.01 & 67 & 0.93 \\
\hline MUF- $1 \%$ CNF & 45.00 & 0.45 & 54.55 & - & 45.2 & 1.00 & 67 & 8.51 \\
\hline UF-3\% CNF & 26.14 & 0.79 & 73.07 & 0.65 & 26.3 & 3.02 & 119 & 1.41 \\
\hline
\end{tabular}

While a considerable number of publications regarding the reinforcement of polymers with nanofibers from cellulose can be found, literature on cellulose-reinforced adhesives suitable for wood bonding is quite scarce. Richter et al. [19] discussed the application of CNF for reinforcing onecomponent polyurethane and water-based polyvinyl acetate (PVAc) latex wood adhesives. Although both cellulose-containing adhesives performed well in mechanical tests, no significant and consistent improvement of bond line performance compared to reference products could be achieved. The authors identified a similar polarity of fibers and polymer, a quality controlled fiber morphology, and a carefully balanced fiber loading in the range from 1 to $5 \mathrm{wt} \%$ as the critical parameters determining the mechanical properties of CNF reinforced adhesives. In another study [20] performed by the same research group, the suitability of using $\mathrm{CNF}$ to formulate PVAc-adhesive mixtures yielding bond lines with improved heat resistance was studied. A significantly increased storage modulus was found for CNF reinforced PVAc-latex films by dynamic mechanical analysis. Furthermore, lap joint test specimens prepared with cellulose-reinforced adhesive showed significantly enhanced heat resistance. In a very recent study, Atta-Obeng [18] reinforced phenol-formaldehyde (PF) adhesive with microcrystalline cellulose at different loading rates from 0 to $10 \mathrm{wt} \%$. Lap shear tests revealed an increase in strength with the addition of cellulose. On the other hand, particle boards produced with cellulose-filled PF showed inferior mechanical properties in static bending tests and higher thickness swelling than boards bonded with pure PF. This was attributed to a less pronounced spring back effect during hotpressing. The cellulose reinforcement seems to restrict the spring back of the board after the compression stress imposed by the hot-press is released. The author concluded that this leads to a debonding of wood particles and adhesive resulting in a decreased board performance.

Own investigations [21] revealed that the addition of $5 \mathrm{wt} \%$ of CNF to a commercially used UF adhesive enables the preparation of solid wood adhesive joints with significantly increased lap shear strength according to EN 302-1 [22]. Since the deformation to failure was significantly higher for the CNF reinforced specimens, it was concluded that the UF adhesive was possibly toughened by the addition of fibrillated cellulose. In a follow-up study [23], the effect of CNF addition on the specific fracture energy of solid wood adhesive bonds was examined. Fracture energy was determined from flat double cantilever beam (DCB) specimens as

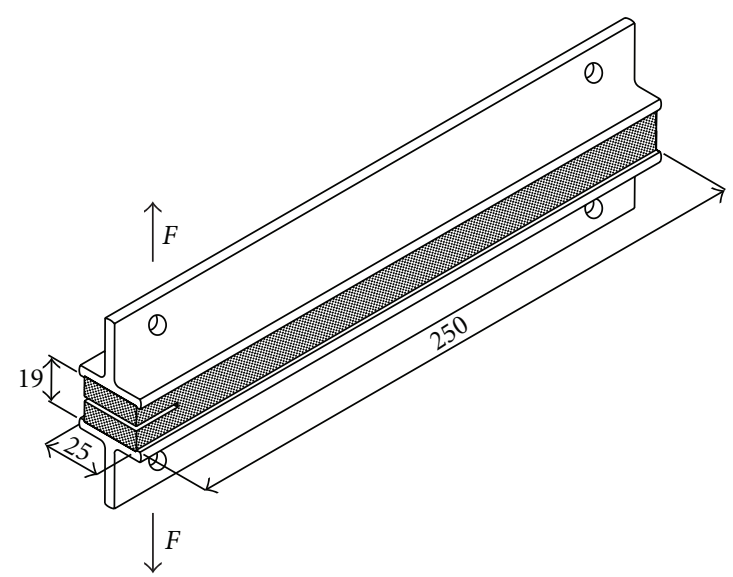

FIgure 1: Test setup for the determination of fracture mechanical properties. Two $T$-shaped steel sections were bonded to the notched test specimen to ensure a uniform introduction of forces. A tensile load was applied after the bolts of the test grips had been inserted into the holes at the front end of the steel section.

described by Gagliano and Frazier [24]. Since fracture energy of UF bonds filled with $2 \mathrm{wt} \%$ of CNF was up to $45 \%$ higher compared to pure UF bonds, this study proved the feasibility of toughening UF by the addition of CNF.

The aim of the present study was to investigate whether the addition of CNF to formaldehyde-based wood adhesives results in improved mechanical properties of wood-based panels produced with these. Lab-scale particle boards and OSB were prepared with commercially available UF and MUF adhesives which were reinforced by adding small amounts of CNF. The rheological behavior of adhesive mixtures and the mechanical properties of the final boards were investigated.

\section{Material and Methods}

2.1. Preparation of Cellulose Nanofibers. The starting material used to prepare CNF was never-dried dissolving grade beech pulp (Lenzing AG, Lenzing, Austria) with a dry content of about $50 \mathrm{wt} \%$. The pulp was initially soaked in distilled water for 2 hours. Thereafter, larger fiber aggregates were disintegrated using an Ultra-Turrax mixer operated at $21500 \mathrm{~min}^{-1}$ for $3 \mathrm{~min}$. The dry content of the fiber suspension was set to $0.5 \mathrm{wt} \%$. To obtain nanofibers, the suspension was fibrillated 


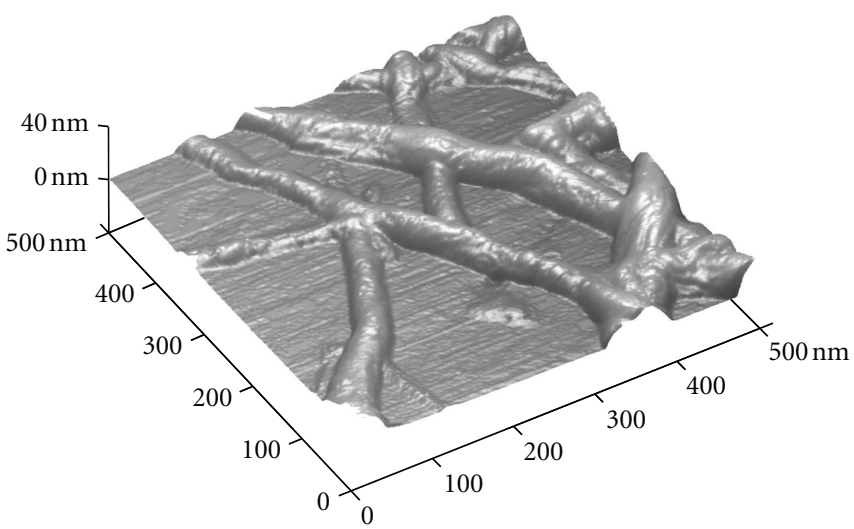

FIGURE 2: AFM micrograph of cellulose nanofibers obtained by high-pressure homogenization of never-dried beech pulp. Mean fiber diameter is $35 \mathrm{~nm}$.

by 30 passes through a high-pressure laboratory homogenizer (APV 1000, APV Manufacturing Sp. z o.o., Bydgoszcz, Poland) operated at a pressure of 700-800 bar. The homogenized suspension was air-dried at $70-80^{\circ} \mathrm{C}$ until a cellulose content of $1.5 \pm 0.1 \mathrm{wt} \%$ was reached. The suspension was subsequently used for the preparation of cellulose-filled adhesive mixtures.

Nanofibers were characterized using Atomic Force Microscopy (AFM). A single drop of a $0.002 \%$ CNF suspension was spread on a mica disk and left to dry at room temperature until the water was evaporated. AFM imaging was performed on a Dimension Icon AFM (Bruker Corp., Santa Barbara, USA). Images were taken in tapping mode with a scan rate of 0.5-0.6 lines per second using a standard silicon cantilever (TESPA, Bruker Corp., Santa Barbara, USA).

\subsection{Preparation and Characterization of Adhesive Mixtures.} For the preparation of lab-scale particle boards, a UF adhesive used in particle board industry (Prefere 10F102, Dynea Austria GmbH, Krems, Austria) was applied. Adhesive mixtures with a cellulose content of 1 and $3 \%$ by weight of solid resin were prepared by adding the respective amount of the $1.5 \%$ CNF suspension to the adhesive. The cellulosefilled adhesive was mixed with a hand blender for $3 \mathrm{~min}$ to achieve a proper distribution of CNF in the UF matrix. A solution of $10 \mathrm{wt} \%$ ammonium nitrate in water was used as a hardener for the UF resin. OSB panels were prepared with a powdery MUF adhesive (Prefere 4681, Dynea AS, Lillestrøm, Norway) without any additional hardener. The cellulose content was $1 \%$ by weight of solid resin. The composition of the individual adhesive mixtures is given in Table 1 .

For further characterization, the gel time and viscosity of the adhesive mixtures were determined. For measuring the gel time, about $2.6 \mathrm{~g}$ adhesive were poured in a test tube and properly mixed with solid ammonium nitrate $(2.3 \%$ by weight of solid resin) as a hardener. The test tube was immersed in a boiling water bath, and the time from immersion to adhesive gelation was determined. Three measurements were taken for each adhesive mixture. Viscosity measurements were performed on a Bohlin CVO Rheometer
(Bohlin Instruments, Pforzheim, Germany). A cone/plate measuring system with a gap size of $0.15 \mathrm{~mm}$ was used for all measurements. A quantity of $1.2-1.3 \mathrm{~mL}$ of liquid adhesive was spread on the plate, and the viscosity was averaged over a $30 \mathrm{~s}$ time span. This procedure was repeated 5 times for each mixture. All adhesives were measured without hardener addition at $20^{\circ} \mathrm{C}$ and a constant shear rate of $10 \mathrm{~s}^{-1}$.

2.3. Board Preparation. For particle board preparation, industrial wood particles (Fritz Egger GmbH, Unterradlberg, Austria) with a particle size between 0.63 and $14 \mathrm{~mm}$ were air dried to a moisture content of $4.2 \%$. The dried particles were coated with adhesive in a rotating drum by spray application of the UF adhesive mixture. To remove excessive water, the glued particles were dried by blowing cold air into the rotating gluing drum. After a drying time of $2 \mathrm{~h}$ and $12 \mathrm{~h}$ for UF containing 1 and $3 \mathrm{wt} \%$ CNF, respectively, the moisture content of the particles was reduced to about $8 \%$. Only after that, the hardener solution was sprayed onto the glued particles which again caused an increase in moisture content to a target value of $10 \pm 1 \%$. After spraying the hardener solution, the particles were rotated for another $2 \mathrm{~min}$ to ensure a uniform distribution of hardener across the particles. The glued particles were formed to a mat and hot-pressed at a temperature of $200^{\circ} \mathrm{C}$ and a pressure of $4.5 \mathrm{MPa}$. Pressing time was $150 \mathrm{~s}$ for all boards. In total, 9 particle boards $(500 \times$ $430 \times 14 \mathrm{~mm}^{3}$ ) were prepared, that is, three boards each with pure UF, UF-1\%CNF, and UF-3\%CNF. The adhesive content of all particle boards was $10 \%$ of solid resin based on ovendry wood.

OSB panels were prepared from two different fractions of lab-manufactured Pine strands (Pinus sylvestris L.). The strands for the core and surface layer were initially dried to a moisture content of 4.9 and $3.3 \%$, respectively. The two fractions were coated with adhesive separately using the same application procedure as for particle boards. The coated strands were dried to a moisture content of $10 \pm 1 \%$ and formed to a mat with a three-layered structure $\left(0^{\circ} / 90^{\circ} / 0^{\circ}\right)$. Parameters used for hot-pressing were the same than for particle boards with the exception that the pressing time was increased to $220 \mathrm{~s}$. Three OSB panels $\left(500 \times 430 \times 19 \mathrm{~mm}^{3}\right)$ 


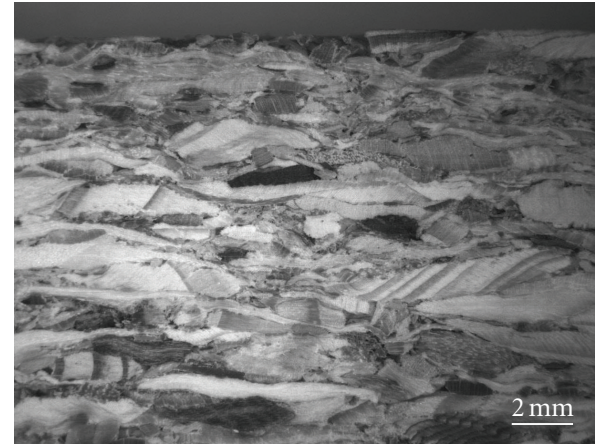

(a)

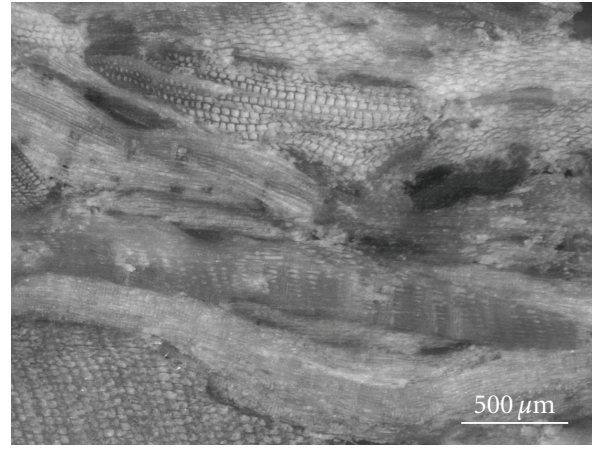

(c)

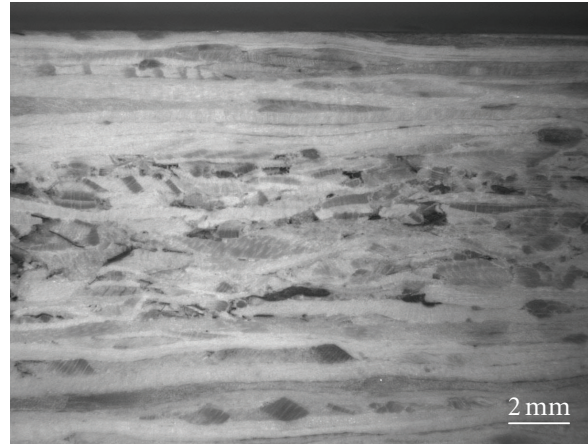

(b)

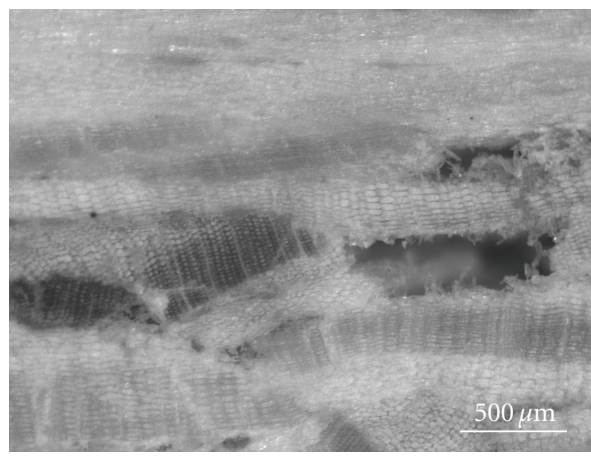

(d)

FIGURE 3: Incident-light micrographs showing the cross-section of particle board $(a+c)$ and OSB $(b+d)$. While wood particles have no preferred orientation in particle board (a), particles are oriented in a crosswise way in case of OSB, yielding a 3-layered structure (b).

with an adhesive content of $8 \%$ were produced with pure MUF and MUF-1\%CNF. All boards were stored in a climate chamber at $20^{\circ} \mathrm{C}$ and $65 \%$ relative humidity until equilibrium moisture content was reached.

2.4. Determination of Board Properties. The density and $24 \mathrm{~h}$ thickness swelling of the boards were determined according to the European standards EN 323 [25] and EN 317 [26], respectively. For this purpose, 18 particle boards and 15 OSB specimens were cut for each adhesive mixture. Density and thickness swelling were subsequently determined from the same specimens.

Mechanical testing included the determination of internal bond, bending strength, fracture energy, and fracture toughness. Internal bond and bending strength were determined in accordance with EN 319 [27] and EN 310 [28]. Internal bond strength was tested on a Zwick/Roell Z100 universal testing machine equipped with a $5 \mathrm{kN}$ load cell, whereas bending tests were performed on a Zwick/Roell Z020. For the fracture mechanical tests, specimens with a length of $250 \mathrm{~mm}$ and a width of $25 \mathrm{~mm}$ were cut from the boards and a $20 \mathrm{~mm}$ long notch was cut at one end of each specimen. The notched specimens were bonded to T-shaped steel sections with a cyanoacrylate adhesive (Loctite 431, Henkel Central Eastern Europe GmbH, Vienna, Austria) in order to attach the specimens to the test grips (Figure 1). Fracture mechanical tests were performed on a Zwick/Roell Z100 testing machine equipped with a $2.5 \mathrm{kN}$ load cell. The particle board specimens were initially loaded with a speed of $1 \mathrm{~mm} \cdot \mathrm{min}^{-1}$, and, after a $30 \%$ drop in load, the speed was gradually increased to $100 \mathrm{~mm} \cdot \mathrm{min}^{-1}$. The criterion used to define the end of the test was the achievement of a lower force limit of $5 \mathrm{~N}$ or a maximum displacement of $50 \mathrm{~mm}$, respectively. For testing of OSB, parameters have been slightly modified, that is, a $5 \mathrm{kN}$ load cell was used, the testing speed was increased from 1 to $10 \mathrm{~mm} \cdot \mathrm{min}^{-1}$ after a $50 \%$ drop in load, and a maximum displacement of $20 \mathrm{~mm}$ was used as a cancellation criterion. Fracture energy of each sample was calculated by integration of the load-displacement curve recorded during testing. The results reflect the fracture work $W_{f}(\mathrm{~J})$ needed to separate the specimen into two parts under mode I loading. The fracture toughness, that is, the critical stress intensity factor $K_{\mathrm{Ic}}\left(\mathrm{MPa} \cdot \mathrm{m}^{1 / 2}\right)$, was calculated according to (1) which was derived from finite element (FEM) simulations performed by Rathke et al. [29]:

$$
\begin{aligned}
K_{\mathrm{Ic}}=F_{\max }[ & 6.568 \cdot 10^{-5}+2.082 \cdot 10^{-7} \frac{k_{\text {init }}}{b} \\
& -1.498 \cdot 10^{-10}\left(\frac{k_{\text {init }}}{b}\right)^{2} \\
& \left.+5.253 \cdot 10^{-14}\left(\frac{k_{\text {init }}}{b}\right)^{3}\right],
\end{aligned}
$$

where $F_{\max }$ reflects the maximum applied load, $k_{\text {init }}$ is the initial slope of the load-displacement curve, and $b$ is 


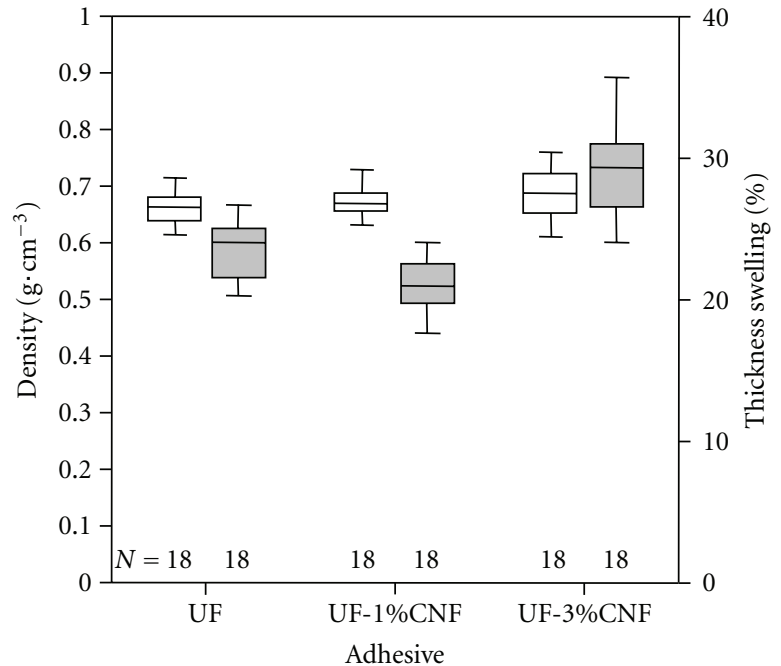

Density

Swelling

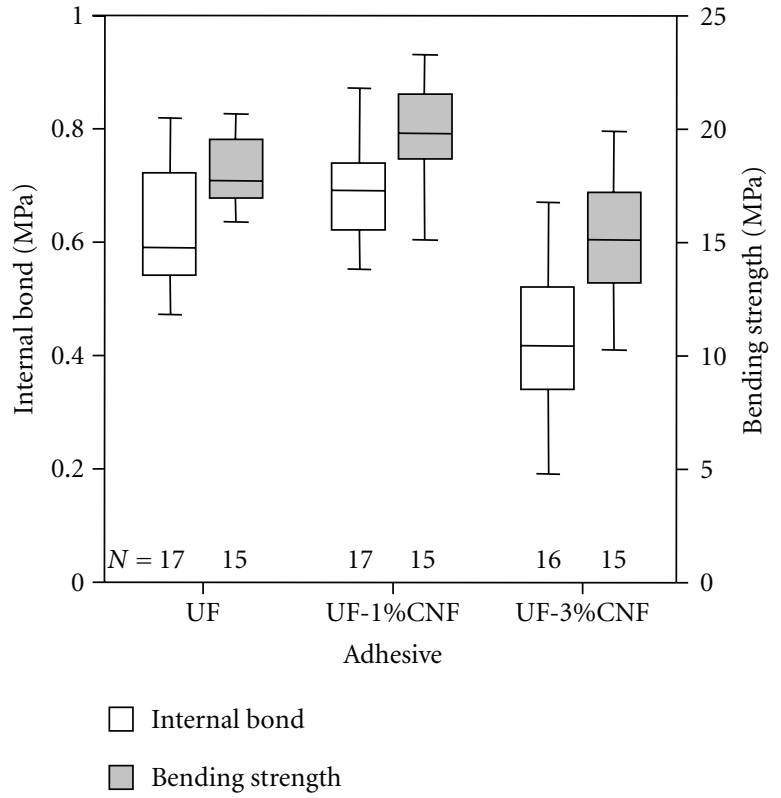

(b)

(a)

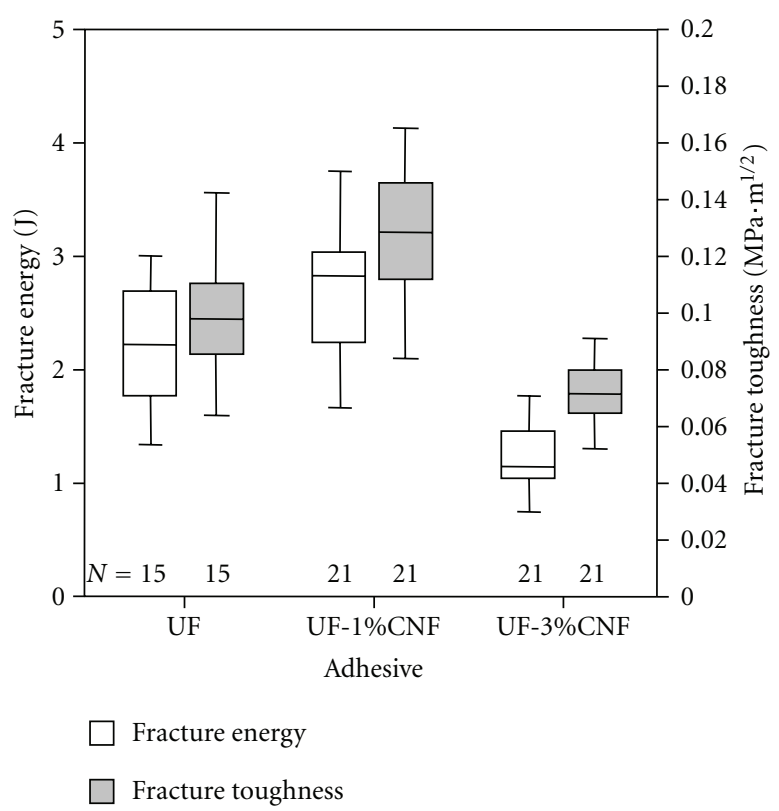

(c)

Figure 4: Mechanical properties of lab-scale particle boards: density and $24 \mathrm{~h}$ thickness swelling (a), internal bond and bending strength (b), as well as fracture mechanical properties (c). The number of specimens tested for each group is given by $N$.

the specimen width. For all of the tested parameters, mean values were calculated for each group of specimens and compared by one-way analysis of variance (ANOVA, $P \leq 0.05$ ) followed by a Scheffé test.

\section{Results and Discussion}

3.1. Properties of Adhesive Mixtures. As shown in Figure 2, the CNF used to prepare cellulose-reinforced adhesive mixtures had diameters ranging from 20 to $65 \mathrm{~nm}$ with an average of $35 \mathrm{~nm}$. The addition of the CNF suspension had a significant effect on the rheological behavior and curing properties of the adhesives. Regarding UF, the viscosity increased steadily with increasing cellulose content although the solid resin content of the mixtures decreased substantially due to the amount of extra water from the suspension. The much lower solid resin content may also be responsible for the slower curing of cellulose-filled UF reflected by the longer gel times (Table 1). In the case of MUF, the increase in viscosity is even more obvious since the solid resin content was 


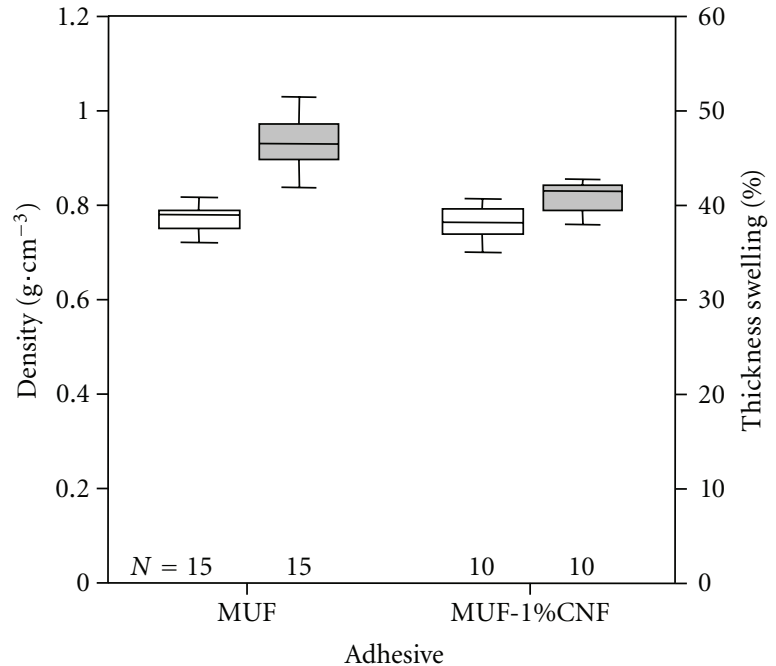

Density

Thickness swelling

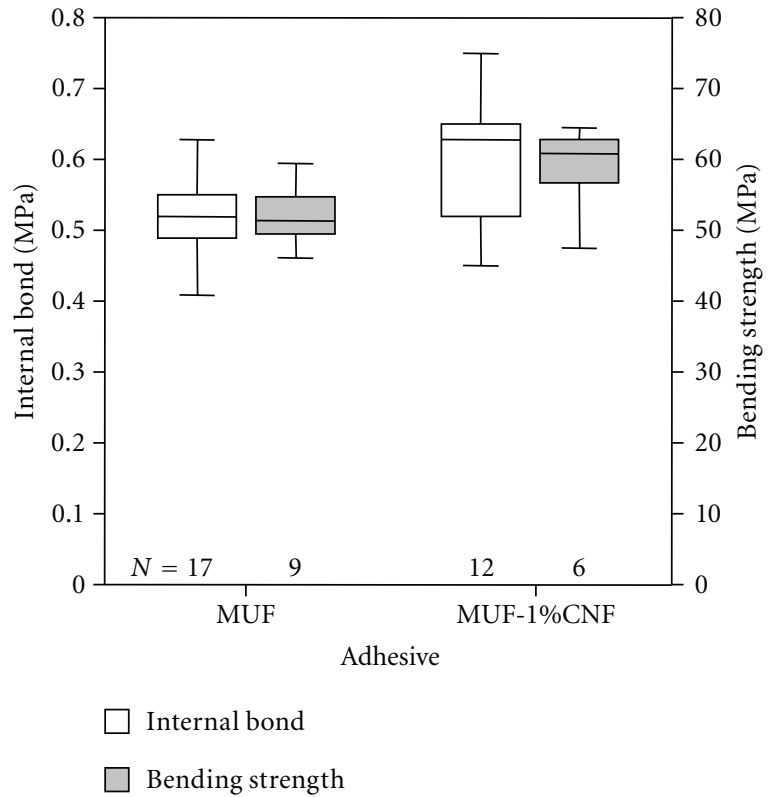

(b)

(a)

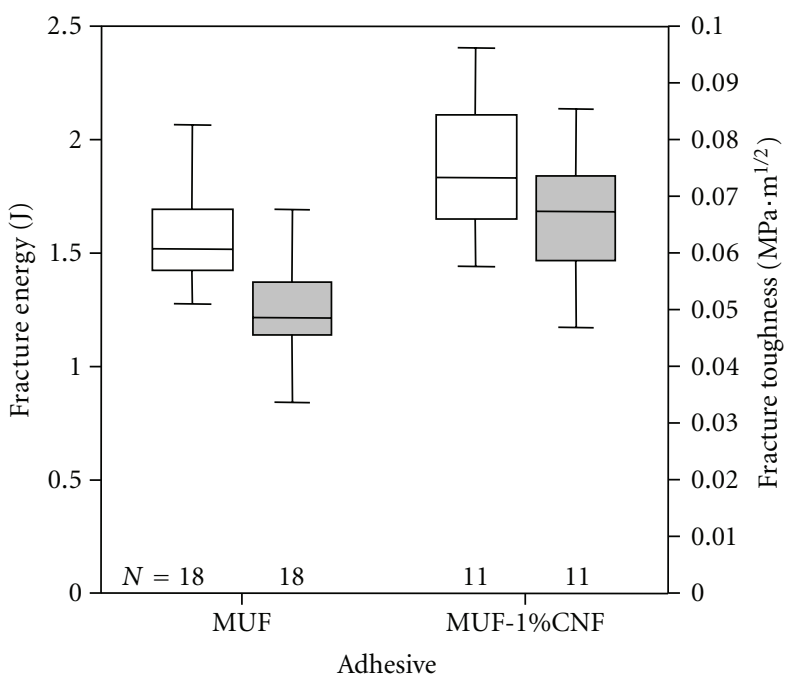

Fracture energy

Fracture toughness

(c)

FIGURE 5: Mechanical properties of lab-scale OSB: density and $24 \mathrm{~h}$ thickness swelling (a), internal bond and bending strength, (b) as well as fracture mechanical properties (c). The number of specimens tested for each group is given by $N$.

the same for the pure and the CNF filled adhesive. Thus, it can be deduced that, at a given solid resin content, the addition of only a few percent of CNF causes a substantial viscosity increase. This was to be expected and agrees well with previous findings $[18,21,23]$. Since the viscosity must be low enough to keep the adhesive applicable to the wood surface, the rapidly increasing viscosity limits the amount of CNF that can be added to a small percentage.

3.2. Mechanical Board Properties. Due to the structural differences between particle board and OSB (Figure 3), the results are discussed separately. The mean density of all particle boards produced in this study was $0.67 \pm 0.03 \mathrm{~g} \cdot \mathrm{cm}^{-3}$. While boards with CNF filled and pure UF resin showed a similar density, clear differences between the individual groups were found in thickness swelling (Figure 4). Boards prepared with UF-1\% CNF demonstrated a reduced swelling compared to the nonreinforced reference. Regarding the internal bond, this group delivered about $10 \%$ higher values $(0.68 \pm 0.10 \mathrm{MPa})$ than the reference boards $(0.62 \pm$ $0.10 \mathrm{MPa}$ ). Also, the bending strength was enhanced from $18.4 \pm 2.0 \mathrm{MPa}$ to $19.5 \pm 2.7 \mathrm{MPa}$. The most obvious 
improvements were achieved in the fracture mechanical properties. The fracture energy increased by $20 \%$ and the fracture toughness even by $28 \%$ due to the addition of $1 \mathrm{wt} \%$ cellulose. In the latter case, the improvement is also significant in a statistical sense (ANOVA, $P \leq 0.05$ ). Contrary to a previous study [23] where a higher variability of fracture energy values was found for CNF reinforced wood adhesive bonds, this is not the case in the present work. Overall, the cellulose addition did not really affect the variation of mechanical board properties. Whereas particle boards with UF$1 \%$ CNF generally outperformed the reference boards, the inverse effect was observed for boards with UF-3\% CNF. This group showed significantly worse mechanical and fracture mechanical properties. It is assumed that this deterioration is not directly induced by the higher CNF content but can be explained by the long drying time of the glued wood particles prior to hot-pressing. Since most of the water originally contained in the adhesive mixture was removed during drying, the particle surface dried off almost completely leading to a perceptible reduction of cold tacking and probably a reduced cohesion of wood particles in the final board. In addition, a nonnegligible precuring of the adhesive may have occurred during the $12 \mathrm{~h}$ of drying. Hence, it is concluded that although a CNF content of $1 \%$ worked best in this study, this is not necessarily a general optimum. Mechanical board properties might be further improved by using a higher CNF percentage. As outlined above, the continuously increasing viscosity is the limiting factor in this regard. In the present work, the adhesive mixtures contained considerable amounts of water to keep them sprayable, which in turn generated problems associated with particle drying.

Just like for particle boards, the cellulose reinforcement did not affect the density of OSB specimens but had a statistically significant impact on their swelling behavior and mechanical properties as displayed in Figure 5. The overall thickness swelling of both, the reinforced and nonreinforced OSB specimens, exceeds $40 \%$ and is therefore on a very high level especially when the threshold values according to EN 300 [30], that is, $25 \%$ for OSB 1 and $12 \%$ for OSB 4 , are taken into account. To some extent, this can be explained by the comparatively high board density of $0.77 \pm 0.03 \mathrm{~g} \cdot \mathrm{cm}^{-3}$ since thickness swelling of wood-based panels is generally considered to be positively correlated to the board density [31-33]. However, the addition of $1 \mathrm{wt} \%$ cellulose results in a decreased swelling. The ANOVA $(P \leq 0.05)$ revealed significant performance improvements for all of the mechanical and fracture mechanical parameters tested. Internal bond strength increased from $0.51 \pm 0.09 \mathrm{MPa}$ to $0.60 \pm 0.10 \mathrm{MPa}$ and bending strength from $50.8 \pm 5.7 \mathrm{MPa}$ to $59.0 \pm 6.1 \mathrm{MPa}$ which is equal to a $16 \%$ improvement in both cases. Fracture energy and fracture toughness increased by 25 and $28 \%$, respectively.

\section{Conclusions}

At a given solid resin content, CNF filled adhesives generally demonstrate a substantially higher viscosity than the corresponding adhesives without cellulose thus limiting the addition level of CNF. The mechanical performance of lab-manufactured particle boards and OSB panels could be significantly enhanced, whereas a CNF content of $1 \mathrm{wt} \%$ delivered the best results. The addition of cellulose primarily improved the fracture energy and fracture toughness of the boards, indicating that wood-based panels can be substantially toughened by using a CNF filled adhesive. Regarding the panel type, CNF reinforcement worked better for OSB than for particle boards. Obviously, the combination of powdery MUF adhesive and larger-sized wood particles is best suited for achieving the optimum reinforcement effect.

\section{Acknowledgments}

The authors gratefully acknowledge financial support by the Austrian Science Fund (FWF) under Grant P22516-N22. Many thanks go to Alexander Klingler and Eva-Marieke Lems for their support in the production of wood-based panels and Michael Obersriebnig for taking the AFM pictures. They would also like to thank Johann Moser (Dynea Austria $\mathrm{GmbH}$ ) for providing wood particles and adhesives.

\section{References}

[1] UNECE/FAO, "Geneva Timber and Forest Study Paper 27: Forest products annual market review 2010-2011," 2011, http://www.unece.org/fileadmin/DAM/publications/timber/ FPAMR_2010-2011_HQ.pdf.

[2] E. Serrano and P. J. Gustafsson, "Influence of bondline brittleness and defects on the strength of timber finger-joints," International Journal of Adhesion and Adhesives, vol. 19, no. 1, pp. 9-17, 1999.

[3] E. Serrano, "A numerical study of the shear-strength-predicting capabilities of test specimens for wood-adhesive bonds," International Journal of Adhesion and Adhesives, vol. 24, no. 1, pp. 23-35, 2004.

[4] U. Müller, A. Sretenovic, A. Vincenti, and W. Gindl, "Direct measurement of strain distribution along a wood bond linepart 1: shear strain concentration in a lap joint specimen by means of electronic speckle pattern interferometry," Holzforschung, vol. 59, no. 3, pp. 300-306, 2005.

[5] R. O. Ebewele, B. H. River, G. E. Myers, and J. A. Koutsky, "Polyamine-modified urea-formaldehyde resins-II. Resistance to stress induced by moisture cycling of solid wood joints and particleboard," Journal of Applied Polymer Science, vol. 43, no. 8, pp. 1483-1490, 1991.

[6] R. O. Ebewele, B. H. River, and G. E. Myers, "Polyaminemodified urea-formaldehyde-bonded wood joints-III. Fracture toughness and cyclic stress and hydrolysis resistance," Journal of Applied Polymer Science, vol. 49, no. 2, pp. 229-245, 1993.

[7] R. O. Ebewele, B. H. River, and G. E. Myers, "Behavior of amine-modified urea-formaldehyde-bonded wood joints at low formaldehyde/urea molar ratios," Journal of Applied Polymer Science, vol. 52, no. 5, pp. 689-700, 1994.

[8] C. Simon, B. George, and A. Pizzi, "UF/pMDI wood adhesives: networks blend versus copolymerization," Holzforschung, vol. 56, no. 3, pp. 327-334, 2002.

[9] S. Das, L. M. Matuana, and P. Heiden, "Thermoplastic polymers as modifiers for urea-formaldehyde wood adhesives. III. In situ thermoplastic-modified wood composites," Journal of Applied Polymer Science, vol. 107, no. 5, pp. 3200-3211, 2008. 
[10] D. Dziurka and R. Mirski, "UF-pMDI hybrid resin for waterproof particleboards manufactured at a shortened pressing time," Drvna Industrija, vol. 61, no. 4, pp. 245-249, 2010.

[11] Y. Zhang, J. Gu, Y. Zuo, M. Di, H. Tan, and L. Zhu, "Mechanical properties of wheat straw particleboard using composite adhesives," Advanced Materials Research, vol. 113-116, pp. 2096-2099, 2010.

[12] I. Kaur, B. N. Misra, A. Sarkar, G. S. Chauhan, and B. Singh, "Preparation and characterization of forest waste pine cellulosic fiber-UF resin based polymer composites," Science and Engineering of Composite Materials, vol. 10, no. 6, pp. 437-451, 2002.

[13] A. S. Singha and V. K. Thakur, "Effect of fibre loading on urea-formaldehyde matrix based green composites," Iranian Polymer Journal, vol. 17, no. 11, pp. 861-873, 2008.

[14] A. S. Singha and V. K. Thakur, "Mechanical properties of natural fibre reinforced polymer composites," Bulletin of Materials Science, vol. 31, no. 5, pp. 791-799, 2008.

[15] A. S. Singha and V. K. Thakur, "Fabrication and characterization of $\mathrm{H}$. sabdariffa fiber-reinforced green polymer composites," Polymer, vol. 48, no. 4, pp. 482-487, 2009.

[16] A. S. Singha, T. K. Vijay, and B. N. Mishra, "Study of Grewia Optiva fiber reinforced Urea-Formaldehyde composites," Journal of Polymer Materials, vol. 26, no. 1, pp. 81-90, 2009.

[17] V. K. Thakur and A. S. Singha, "Natural fibres-based polymers-part i-mechanical analysis of pine needles reinforced biocomposites," Bulletin of Materials Science, vol. 33, no. 3, pp. 257-264, 2010.

[18] E. Atta-Obeng, Characterization of phenol formaldehyde adhesive and adhesive-wood particle composites reinforced with microcrystalline cellulose, M.S. thesis, Auburn University, 2011.

[19] K. Richter, N. Bordeanu, F. López-Suevos, and T. Zimmermann, "Performance of cellulose nanofibrils in wood adhesives," in Proceedings of the Swiss Bonding, pp. 239-246, Rapperswil, Switzerland, 2009.

[20] F. López-Suevos, C. Eyholzer, N. Bordeanu, and K. Richter, "DMA analysis and wood bonding of PVAc latex reinforced with cellulose nanofibrils," Cellulose, vol. 17, no. 2, pp. 387$398,2010$.

[21] S. J. Eichhorn, A. Dufresne, M. Aranguren et al., "Review: current international research into cellulose nanofibres and nanocomposites," Journal of Materials Science, vol. 45, no. 1, pp. 133, 2010.

[22] EN 302-1, "Adhesives for load-bearing timber structures-test methods-part 1: determination of bond strength in longitudinal tensile shear strength," Austrian Standards Institute, Vienna, Austria, 2004.

[23] S. Veigel, U. Müller, J. Keckes, M. Obersriebnig, and W. GindlAltmutter, "Cellulose nanofibrils as filler for adhesives: effect on specific fracture energy of solid wood-adhesive bonds," Cellulose, vol. 18, no. 5, pp. 1227-1237, 2011.

[24] J. M. Gagliano and C. E. Frazier, "Improvements in the fracture cleavage testing of adhesively-bonded wood," Wood and Fiber Science, vol. 33, no. 3, pp. 377-385, 2001.

[25] EN 323, "Wood-based panels-determination of density," Austrian Standards Institute, Vienna, Austria, 1993.

[26] EN 317, "Particleboards and fibreboards-determination of swelling in thickness after immersion in water," Austrian Standards Institute, Vienna, Austria, 1993.

[27] EN 319, "Particleboards and fibreboards-determination of tensile strength perpendicular to the plane of the board," Austrian Standards Institute, Vienna, Austria, 1993.

[28] EN 310, "Wood-based panels-determination of modulus of elasticity in bending and of bending strength," Austrian Standards Institute, Vienna, Austria, 1993.
[29] J. Rathke, G. Sinn, M. Weigl, and U. Müller, "Analysing inplane orthotropy of wood based panels by means of fracture mechanics," Manuscript submitted for publication.

[30] EN 300, "Oriented Strand Boards (OSB)—definitions, classification and specifications," Austrian Standards Institute, Vienna, Austria, 1997.

[31] A. F. Halligan, "A review of thickness swelling in particleboard," Wood Science and Technology, vol. 4, no. 4, pp. 301312, 1970.

[32] W. $\mathrm{Xu}$ and P. M. Winistorfer, "A procedure to determine thickness swell distribution in wood composite panels," Wood and Fiber Science, vol. 27, no. 2, pp. 119-125, 1995.

[33] S. Suzuki and K. Miyamoto, "Effect of manufacturing parameters on the linear expansion and density profile of particleboard," Journal of Wood Science, vol. 44, no. 6, pp. 444-450, 1998. 

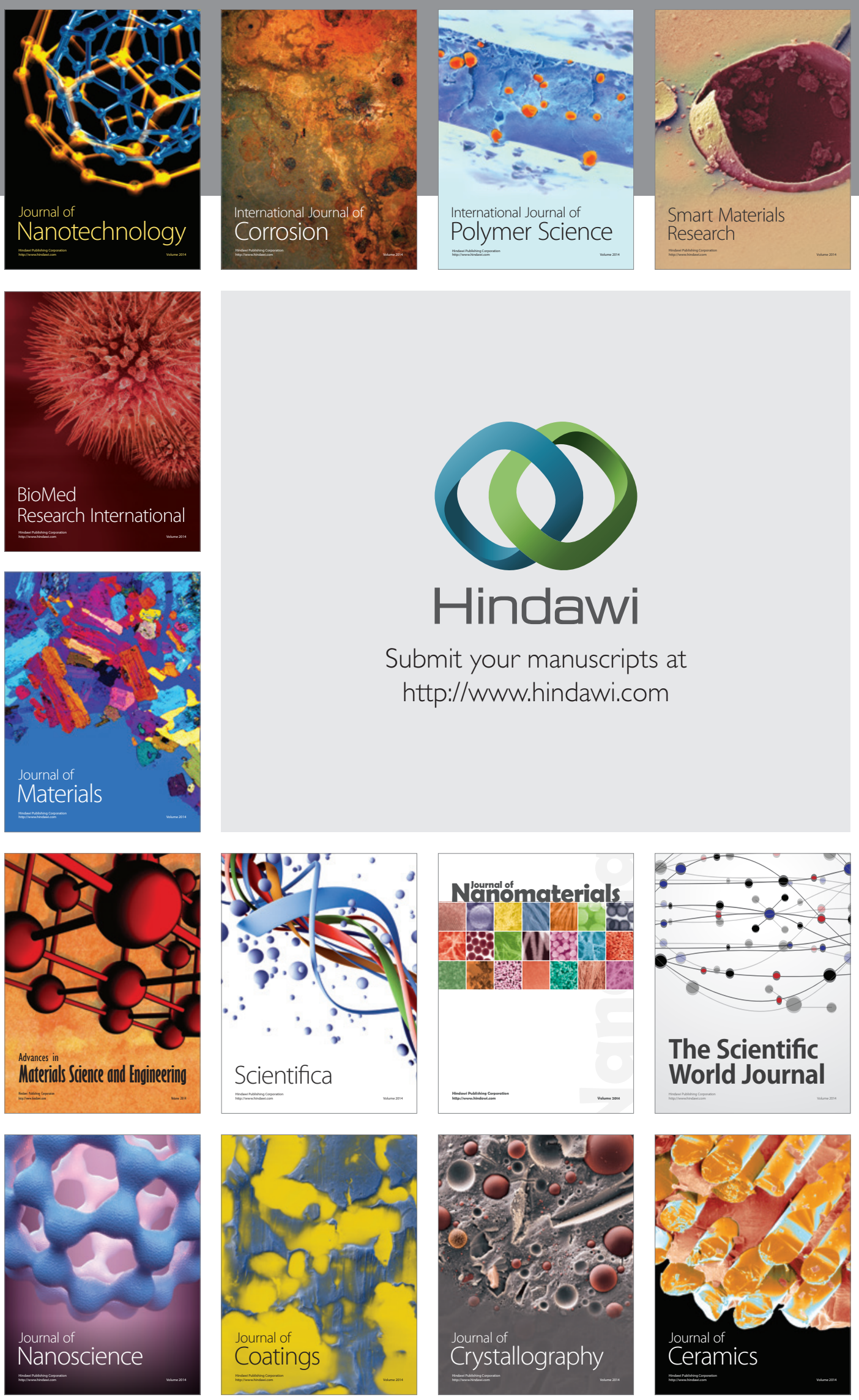

The Scientific World Journal

Submit your manuscripts at

http://www.hindawi.com

\section{World Journal}

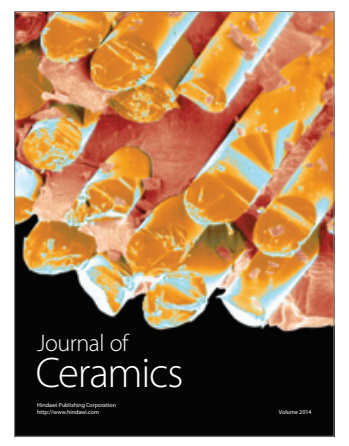

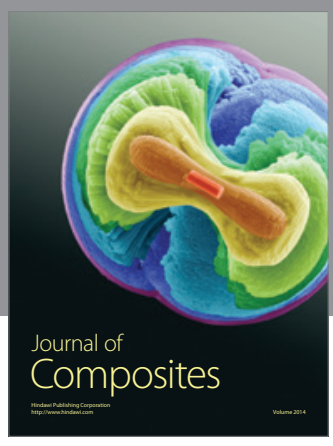
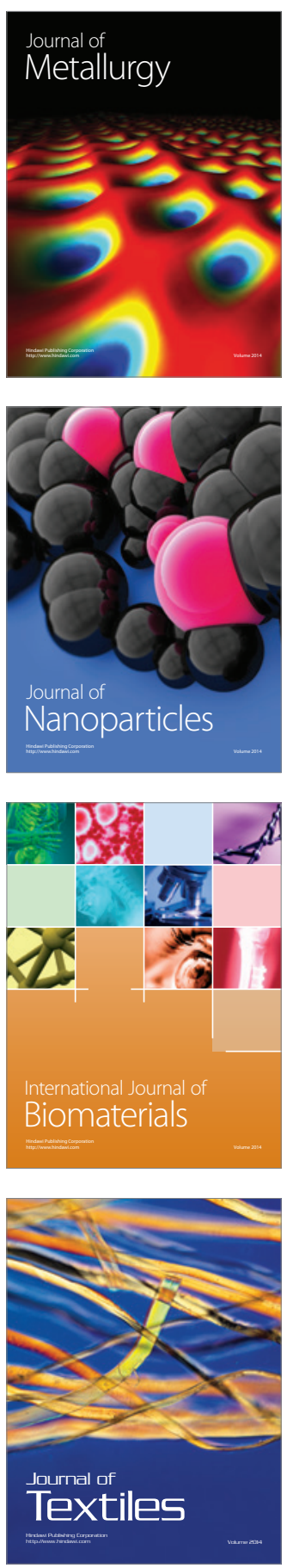